\title{
THREE NEW MEGALYRIDS FROM SOUTH AMERICA (HYMENOPTERA: MEGALYRIDAE)*
}

\author{
By ScotT RichaRd SHaW \\ Department of Entomology, \\ Museum of Comparative Zoology, \\ Harvard University, \\ Cambridge, MA 02138
}

\section{INTRODUCTION}

The neotropical Megalyridae are very rare and virtually unstudied. Some confusion has resulted over the classification of Iseura Spinola, which was based on a single specimen from Brazil (Spinola 1853). Although the wasp is actually a cenocoeline braconid, it was incorrectly classified as a megalyrid by Dalla Torre (1900). This error was perpetuated by subsequent authors (Froggatt 1906, Fahringer 1928, Hedqvist 1959) who continued to treat Iseura as a megalyrid, though they expressed doubts about the correct classification of the genus. The holotype finally was examined by Hedqvist (1967), who correctly determined Iseura to be a braconid (I have also examined the holotype and concur with this identification). Therefore, to date, no authentic megalyrid species are described from South America.

Even so, Nelson and Platnick (1981) characterized the family Megalyridae as "moderately diversified" in South America, citing Kuschel (1960). Although Kuschel (1960) listed Megalyridae as occurring in South America, it is uncertain whether this observation was based on specimens examined, or merely a perpetuation of the incorrect Iseura classification. After surveying the Megalyridae from 25 insect collections, only four neotropical specimens have been found. These represent three new species, each representing a new genus. Although there are few available specimens, it is desirable to describe and name these at the present time, so the taxa may be included in a phylogenetic and biogeographic study of the Megalyridae, currently in progress by the author.

\footnotetext{
*Manuscript received by the editor March 28, 1987.
} 


\section{Materials AND Methods}

Collections and their abbreviations are given in the acknowledgments.

The morphological terminology used in this paper is mostly that of Shaw (in press). Microsculpture terminology is that of Harris (1979). Measurements and ratios are those used by Naumann (1985, in press). Body length (BL) is measured in dorsal view, excluding the antennae and ovipositor. Forewing length (FWL) is measured from the tegula to wing apex. Ovipositor length (OL) is measured from the apex of the hypopygium. Shape of the head is expressed as a ratio of head width (HW) to head length (HL), measured in dorsal view. Size and position of the ocelli is expressed by the ratio of distance between the lateral ocelli (POL) to the distance between compound eye and lateral ocellus (OOL), and the ratio of the maximum diameter of a lateral ocellus (OD) relative to the distance between lateral ocelli (POL). Size of the compound eye is expressed as a ratio of maximum diameter of the compound eye (MAE) relative to the width of the frons (FW), measured as the minimum distance between the compound eyes. Size and shape of the antenna is expressed as flagellar length/width ratios $(\mathrm{F} 1 \mathrm{~L} / \mathrm{F} 1 \mathrm{~W}$, etc.) Mesoscutum shape is expressed by a length/width ratio (MTL/ MTW), and by the ratio of metasoma length relative to body length (MTS/BL).

\section{Family Megalyridae}

Diagnosis: Flagellum 12-segmented; subantennal groove present; mesoscutum usually with a median sulcus (absent in one oriental genus, but always present in neotropical species); pronotum with the mesothoracic spiracle completely surrounded by pronotal cuticle; hind wing venation reduced, $S c+R$ leading to $R 1$ and $R s$ (as in Figs. 4-6).

\section{Key to Neotropical Megalyridae (Females)}

1. Ocular carina absent (Figs. 1-2); apical segment of Rs in forewing indicated only by spectral venation, not sclerotized and tubular to wing margin (Figs. 4-5) $\ldots \ldots \ldots \ldots \ldots \ldots \ldots 2$

Ocular carina present (Fig. 3); apical segment of Rs in forewing sclerotized and tubular to wing margin (Fig. 6) ........... 
2. Ovipositor longer than metasoma length; antenna long and slender (as in Fig. 1) ............. Rigel chiliensis Shaw

Ovipositor shorter than metasoma length; antenna short and compact (as in Fig. 2) ........ Cryptalyra plaumanni Shaw

\section{Genus Rigel Shaw, NEW GENUS}

Type-species: Rigel chiliensis Shaw

Head: Hypognathous, wider than long; clypeus and frons convex, not excavated; frons and ocellar triangle densely punctulate; vertex punctulate to shagreened; occiput, gena, and malar space shagreened; eye ovoid, densely setose; ocular orbital carina absent; malar suture indistinct; subantennal groove broad (Fig. 1), not bordered by distinct carinae; occipital carina present, finely foveolate; occipital carina at base curving away from mandible; postgena narrow; antenna long and slender, apex reaching middle of metasoma; flagellım filiform; mandible 3-toothed; maxillary palpus apparently 4-segmented; labial palpus 3-segmented.

Mesosoma: Mesonotum, axilla, and scutellar disc punctulate to dersely shagreened; median mesoscutal sulcus finely foveolate; axillae meeting at inner angles; pronotum, mesopleuron, metapleuron, and hind coка shagreened; "pronotal" spiracle circular, without an internal fringe of setae; propodeal spiracle elongate, slit-like; propodeum areolate, without tubercles at postero-lateral corners; legs (as in Fig. 1); hind coxa without a longitudinal carina; hind tibial setae prone; fore and middle tibiae not apically rimmed with stout spines; fore and middle tibiae each with one apical spur, hind tibia with two spurs.

Wings (as in Fig. 4) hyaline, without any distinct banding pattern.

Metasoma: Elongate, subcylindrical, slightly compressed; faintly shagreened, but mostly smooth and shining; ovipositor (Fig. 1) much longer than metasoma and slightly arched; ovipositor sheaths long, slender, densely setose, tending to curl.

Etymology: After Rigel, a star in the constellation Orion.

Remarks: Most similar to Megalyridea Hedqvist, described by Hiedqvist (1959) based on a specimen from Cape Province of South Africa. Rigel differs from Megalyridea by lacking a distinct carina along the dorsal margin of the subantennal groove, lacking a row of foveae alorig the genal orbit of the eye, and by having entirely 
hyaline wings. In contrast, Megalyridea has a carina along the dorsal margin of the subantennal groove, a row of foveae along the genal margin of the eye, and fore wing with distinct infumate bands.

Rigel chiliensis, NEW SPECIES

(Figs. 1, 4)

Holotype. Female, CHILE: Las Cruces, Cord. Parral, X.58, (L.E. Pena). (CNC)

Measurements and ratios: BL $3.5 \mathrm{~mm}$; FWL $3.8 \mathrm{~mm}$; OL $5.7 \mathrm{~mm}$; OL/BL 1.63; HW/HL 1.57; POL/OOL 1.33; OD/POL 0.38; FW/MAE 1.13; F1L/F1W 5.2; F2L/F2W 10.0; F3L/F3W 10.0; F1L/F2L 0.65; F2L/F3L 1.0; F11L/F11W 2.67; F12L/F12W 3.0; F11L/F12L 0.89; MSL/MSW 0.57; MTL/MTW 2.7; MTL/BL 0.54 .

Color: Black except trochanters, bases and apices of tibiae, tibial spurs, hypopygium, and ovipositor yellowish brown; tegula and wing venation dark brown.

Paratype female: Same as holotype, except OL $5.9 \mathrm{~mm}$.

Male: Unknown.

Paratype data: 1 female, same data as holotype. (CNC)

Distribution: Chile.

Etymology: Named for its distribution.

\section{Genus Cryptalyra Shaw, NEw Genus}

Type-species: Cryptalyra plaumanni Shaw

Head: Hypognathous, wider than long, globular; clypeus and frons convex, not excavated; frons, ocellar triangle, vertex, occiput, and gena dorsally punctulate; gena ventrally and malar space faintly shagreened; eye ovoid, minutely setose; ocular orbital carina absent; malar suture indistinct; subantennal groove broad, bordered along dorsal margin by a sharp carina (Fig. 2); occipital carina present, finely foveolate dorsally but not ventrally; occipital carina at base curving toward mandible; postgena narrow; antenna very short and compact (Fig. 2), apex barely reaching mesosoma; flagellum filiform, apical flagellomere sharply pointed; mandible 3-toothed; maxillary palpus apparently 4-segmented; labial palpus apparently 2-segmented. 


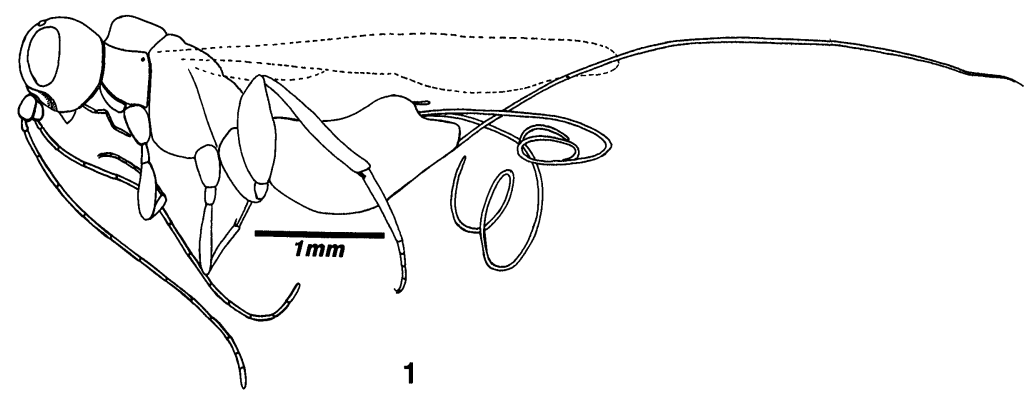

Fig. 1. Rigel chiliensis, lateral habitus.

Mesosoma: Mesonotum, axilla, and scutellar disc densely punctulate; median mesoscutal sulcus finely foveolate; axillae meeting at inner angles; pronotum, mesopleuron, metapleuron, hind coxa, and propodeum basally rugose; "pronotal" spiracle minute and circular, apparently without an internal fringe of setae; propodeal spiracle elongate, slit-like; propodeum apically areolate-rugose, with distinct tubercles at postero-lateral corners; legs (as in Fig. 2); hind coxa without a longitudinal carina; hind tibial setae prone to erect; fore and middle tibiae not apically rimmed with stout spines; fore, middle, and hind tibiae each with one apical spur.

Wings (as in Fig. 5) hyaline, without any distinct banding pattern.

Metasoma: Compact, subcylindrical, not compressed; faintly shagreened, but mostly smooth and shining; ovipositor (Fig. 2) much shorter than metasoma, arched apically; ovipositor sheaths very short, compact, and densely setose, about as long as T7.

Etymology: Derived from "crypto-" (Gr.) meaning hidden, and "lyra" (Gr.), a stringed instrument, as a reference to its short ovipositor.

Remarks: A very autapomorphic genus, quite distinct from any other known megalyrid. Its very short antenna with pointed apical flagellomere, propodeum with postero-lateral tubercles, and very short ovipositor sheaths (Fig. 2) are all unique for Megalyridae. Its relationship to other megalyrids is not readily apparent; however, two putative synapomorphies indicate a possible relationship to the Australian genus Megalyra Westwood: hind coxa rugose and hind tibia with one spur. 


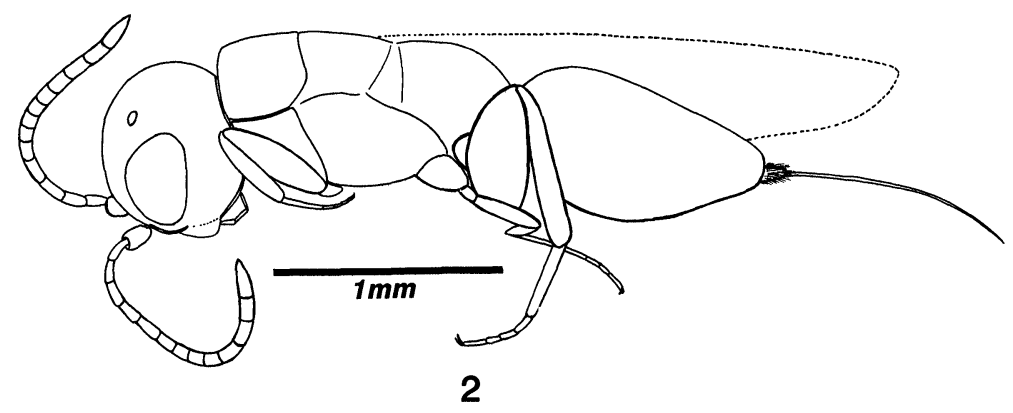

Fig. 2. Cryptalyra plaumanni, lateral habitus

\section{Cryptalyra plaumanni, NEW SPECIES}

(Figs. 2, 5)

Holotype. Female, BRAZIL: Nova Teutonia, 22.II.1941, (F. Plaumann). (AEI)

Measurements and ratios: BL $2.9 \mathrm{~mm}$; FWL $2.6 \mathrm{~mm}$; OL $1.0 \mathrm{~mm}$; OL/BL 0.34; HW/HL 1.52; POL/OOL 1.40; OD/POL 0.36; FW/MAE 0.83; F1L/F1W 1.67; F2L/F2W 1.67; F3L/F3W 1.67; F1L/F2L 1.0; F2L/F3L 1.0; F11L/F11W 1.67; F12L/F12W 3.0; F11L/F12L 0.56; MSL/MSW 0.56; MTL/MTW 1.60; MTL/BL 0.41 .

Color: Brown except ocellar triangle, occipital carina, mesosomal sutures and sulci, meso- and metapleuron, propodeum, hind coxa, and metasoma black; pedicel, basal flagellomeres, tarsi, and ovipositor yellowish brown; wing venation dark brown.

Male: Unknown.

Remarks: Notable for its minute body size and very short ovipositor. It is the smallest megalyrid ever described. Only a few of the undescribed Australian species are nearly as small.

Distribution: Brazil.

Etymology: Named for the collector of the holotype.

Genus Neodinapsis Shaw, NEw GENUS Type-species: Neodinapsis peckorum Shaw 
Head: Hypognathous, wider than long; clypeus and frons convex, not excavated; frons, ocellar triangle, vertex, and occiput foveatereticulate; gena and malar space punctate-rugose; eye ovoid, glabrous; ocular orbital carina present along genal margin from subantennal groove to temple (Fig. 3); space between eye and ocular orbital carina foveate; malar suture faintly indicated at apex of subantennal groove; subantennal groove broad, bordered along dorsal margin by a sharp carina; occipital carina present, finely foveolate; occipital carina at base curving toward mandible; postgena narrow; antenna long and slender, extending at least to middle of mesosoma (F7-12 missing from holotype); flagellum (at least F1-6) filiform; mandible 3-toothed; maxillary palpus apparently 4segmented; labial palpus 3-segmented.

Mesosoma: Mesonotum densely punctate; mesoscutal sulcus finely foveolate; axilla, scutellar disc, and mesopleuron punctulateshagreened; axillae meeting at inner angles; pronotum rugose; "pronotal" spiracle circular, without an internal fringe of setae; metapleuron and hind coxa shagreened; propodeal spiracle elongate, slit-like; propodeum areolate, without tubercles at postero-lateral corners; legs (as in Fig. 3); hind coxa without a longitudinal carina; hind tibial setae prone; fore and middle tibiae not apically rimmed with stout spines; fore and middle tibiae each with one apical spur; hind tibia with two spurs.

Wings (as in Fig. 6) very faintly infumated, but without any distinct banding pattern.

Metasoma: Elongate, subcylindrical, gradually narrower apically but not compressed; faintly shagreened, but mostly smooth and shining; ovipositor (Fig. 3) just slightly longer than metasoma and slightly arched; ovipositor sheaths long, slender, and densely setose.

Etymology: Derived from "neo-" (Gr.) meaning new, and Dinapsis, after the ethiopian megalyrid genus (Waterston 1922).

Remarks: Clearly related to the lineage comprising Dinapsis + Ettchellsia, which shares the following synapomorphies with Neodinapsis: Rs branching from Rs + M (Fig. 6), Rs apically tubular and sclerotized to the wing margin (Fig. 6), and ocular orbital carina present (Fig. 3). Neodinapsis differs from these genera by its shagreened hind coxa without a longitudinal carina, prone hind tibial setae, and areolate propodeum. Dinapsis and Ettchellsia have a 


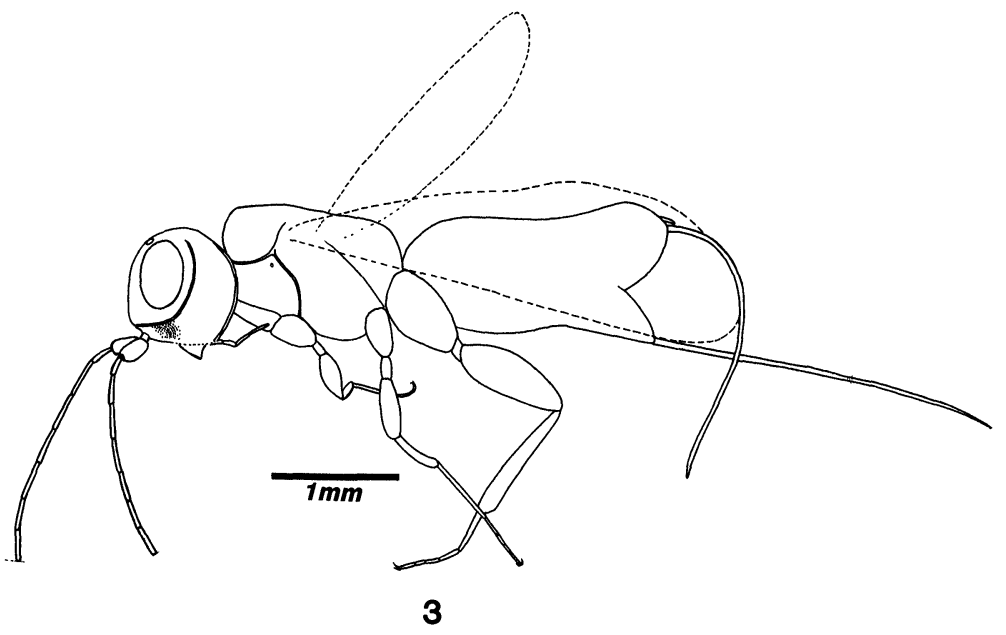

Fig. 3. Neodinapsis peckorum, lateral habitus.

smooth hind coxa with a longitudinal carina, erect hind tibial setae, and carinate propodeum. Neodinapsis is the only known neotropical megalyrid with the Rs apically tubular, sclerotized, and reaching the wing margin (Fig. 6).

\section{Neodinapsis peckorum, NEW SPECIES}

(Figs. 3, 6)

Holotype. Female, CHILE: Cautin, $21 \mathrm{~km}$ NE Pucon, Lago Caburga, 15.XII.84-10.II.85, (S. \& J. Peck), FIT, $600 \mathrm{~m}$, mixed forest remnant. (CNC)

Measurements and ratios: BL $4.3 \mathrm{~mm}$; FWL $3.5 \mathrm{~mm}$; OL $2.8 \mathrm{~mm}$; OL/BL 0.65; HW/HL 1.53; POL/OOL 2.43; OD/POL 0.18; FW/MAE 1.22; F1L/F1W 7.0; F2L/F2W 7.5; F3L/F3W 8.0; F1L/F2L 0.93; F2L/F3L 0.94; (F7-12 missing); MSL/MSW 0.46; MTL/MTW 2.0; MTL/BL 0.51.

Color: Black except tibial spurs, ovipositor, and wing venation brown.

Male: Unknown.

Distribution: Chile.

Etymology: Named for the collectors of the holotype. 

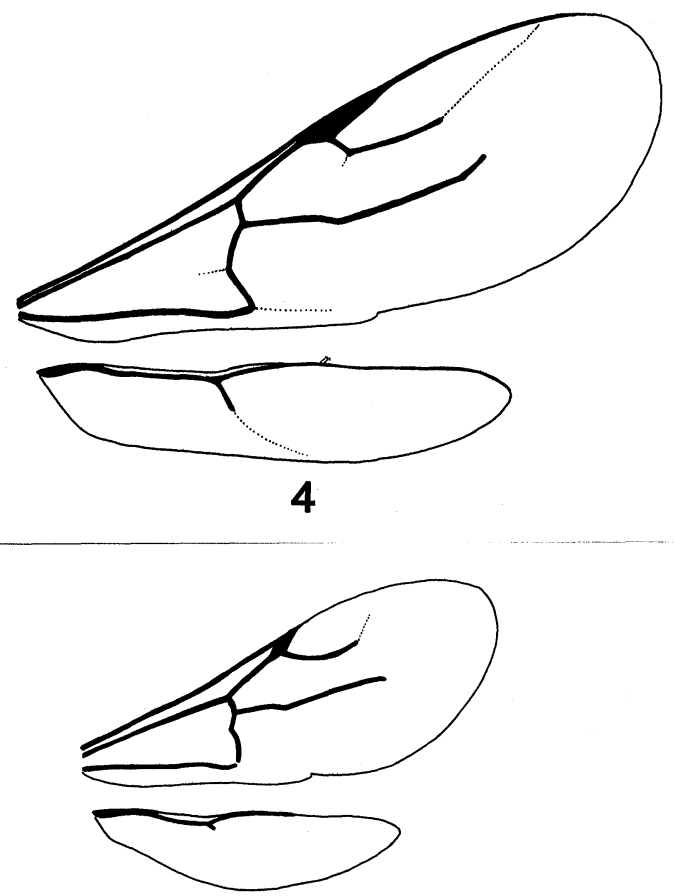

5

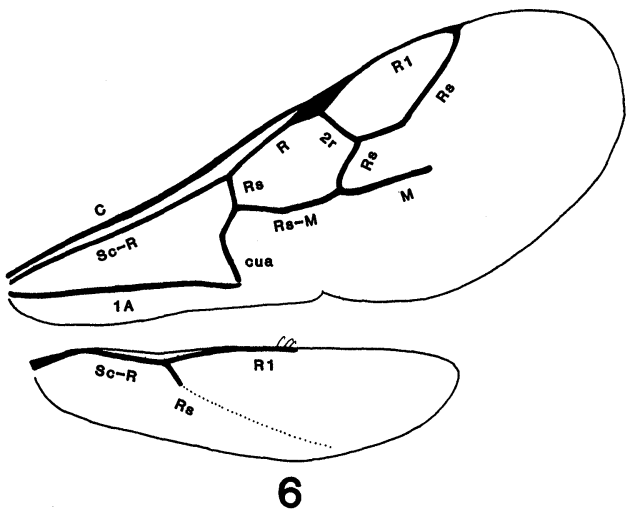

Fig. 4. Rigel chiliensis, wings. Fig. 5. Cryptalyra plaumanni, wings. Fig. 6. Neodinapsis peckorum, wings. 


\section{ACKNOWLEDGMENTS}

The following institutions and individuals loaned the neotropical specimens used in this study:

(AEI) American Entomological Institute, Gainesville, Florida (Dr. Henry Townes)

(CNC) Biosystematics Research Institute, Ottawa, Ontario (Drs. G. Gibson \& L. Masner)

Holotypes of megalyrids from other regions were loaned by:

(AMNH) American Museum of Natural History, New York (M. Favreau)

(ANIC) Australian National Insect Collection, Canberra (Dr. I. Naumann)

(BMNH) British Museum (Natural History), London (Dr. I. Gauld)

(MNHP) Museum National d'Histoire Naturelle, Paris (J. Weulersse)

(NMVM) National Museum of Victoria, Melbourne (Mr. K. Walker)

(QMB) Queensland Museum, Brisbane (Mr. E. Dahms)

(TMB) Termeszettudomanyi Museum, Budapest (Dr. J. Papp)

(UMO) University Museum, Oxford (Dr. C. O'Toole)

(UPP) University of the Philippines, Laguna (Dr. C. Baltazar)

(ZMHB) Zoologisches Museum, Humboldt Universitat, Berlin (Dr. F. Koch)

(ZML) Zoological Museum, Lund (R. Danielsson)

(ZMUA) Zoologisch Museum, Universiteit van Amsterdam (W. Hogenes)

(ZMUC) Zoologisk Museum, Universitets Copenhagen (Dr. B. Petersen)

\section{SUMMARY}

Three new megalyrid genera and species from the Neotropical region are described and illustrated: Rigel chiliensis Shaw, Cryptalyra plaumanni Shaw, and Neodinapsis peckorum Shaw. These are the first Megalyridae described from South America. A diagnosis for the family and a key to neotropical species are given. Preliminary ideas on phylogenetic relationships are discussed. 


\section{REFERENCES}

Dalla Torre, C. G. DE.

1900. Catalogus Hymenopterorum. Volume III: Trigonalidae, Megalyridae, Stephanidae, Ichneumonidae, Agriotypidae, Evaniidae, Pelecinidae. G. Engelmann, Leipzig, $1141 \mathrm{pp}$.

FAHRINGER, J.

1928. Die Megalyriden. Arch. f. Naturgeschichte, Abt. A, 92: 98-123.

FroggatT, W. W.

1906. Notes on the hymenopterous genus Megalyra Westwood, with descriptions of new species. Proc. Linn. Soc. N.S.W. 31: 399-407.

HARris, R. A.

1979. A glossary of surface sculpturing. Occasional Papers in Entomology, No. 28. State of California, Dept. of Food and Agriculture, Sacramento. 31 pp.

Hedqvist, K. J.

1959. Hymenoptera (Ichneumonoidea): Megalyridae. South African Animal Life 6: 485-490.

1967. Notes on Megalyridae (Hym. Ichneumonoidea) and description of new species from Madagascar. Ann. Soc. Ent. Fr. (N.S.) 3: 239-246.

KuSCheL, G.

1960. Terrestrial zoology in southern Chile. Proc. R. Soc. London 152: 540-550.

Naumann, I. D.

1985. The Australian species of Monomachidae (Hymenoptera: Proctotrupoidea), with a revised diagnosis of the family. J. Aust. ent. Soc. 24: 261-274.

in press. A new megalyrid (Hymenoptera: Megalyridae) parasitic on a sphecid wasp in Australia. J. Aust. ent. Soc.

Nelson, G. and N. Platnick.

1981. Systematics and Biogeography. Columbia University Press, New York. $567 \mathrm{pp}$.

SHAW, S. R.

in press. A new genus of Megalyridae (Hymenoptera) from the Oriental and Australian regions, with a commentary on the definition of the family. Syst. Ent.

SPINOla, M.

1853. Compte rendu des Hymenopteres inedits provenants du voyage entomologique de M. Ghiliani. Mem. R. Accad. Sci. Torino 13: 1-29(+).

Waterston, J. C.

1922. A new family of Hymenoptera from South Africa. Ann. \& Mag. Nat. Hist. (9) 10: 418-420. 

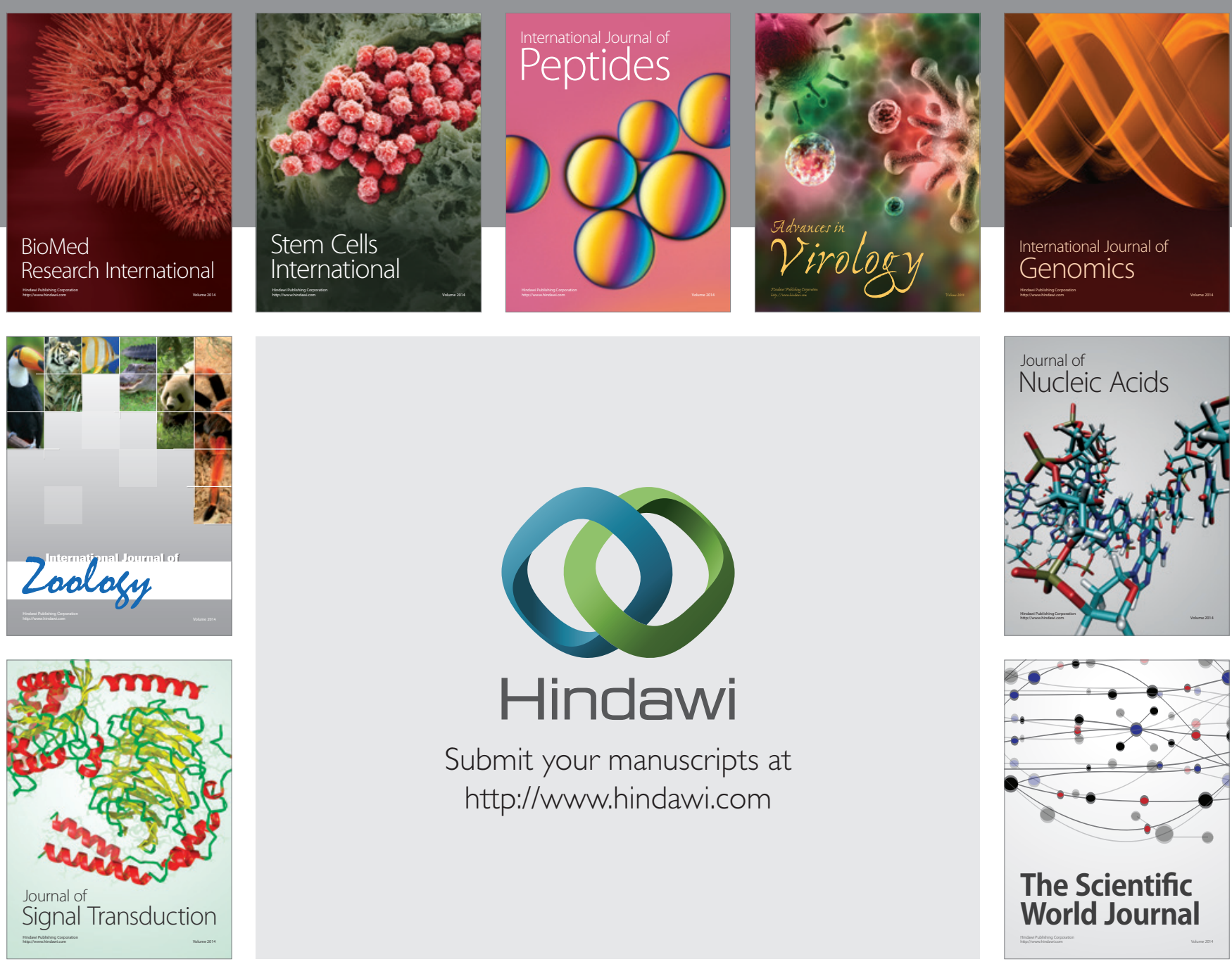

Submit your manuscripts at

http://www.hindawi.com
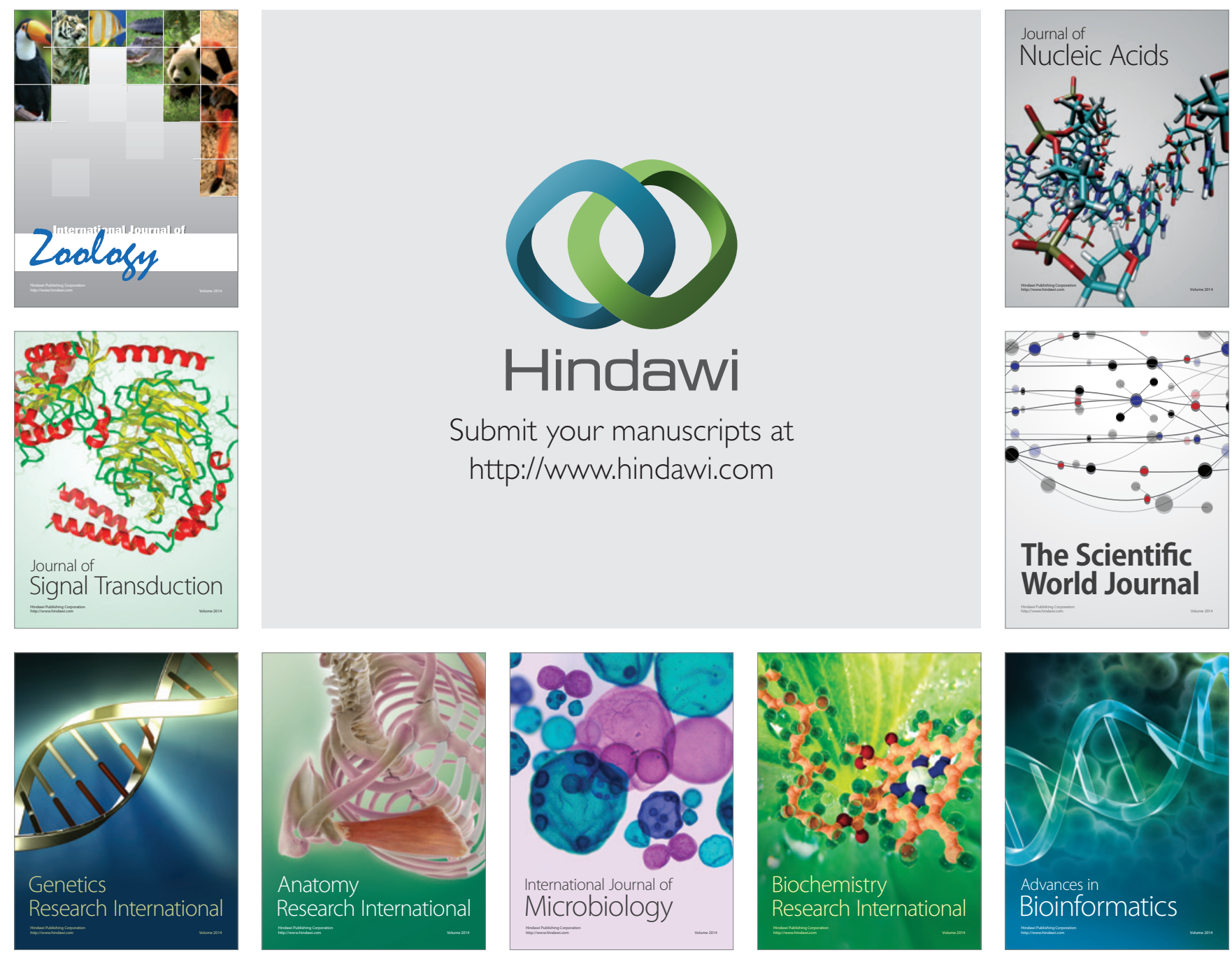

The Scientific World Journal
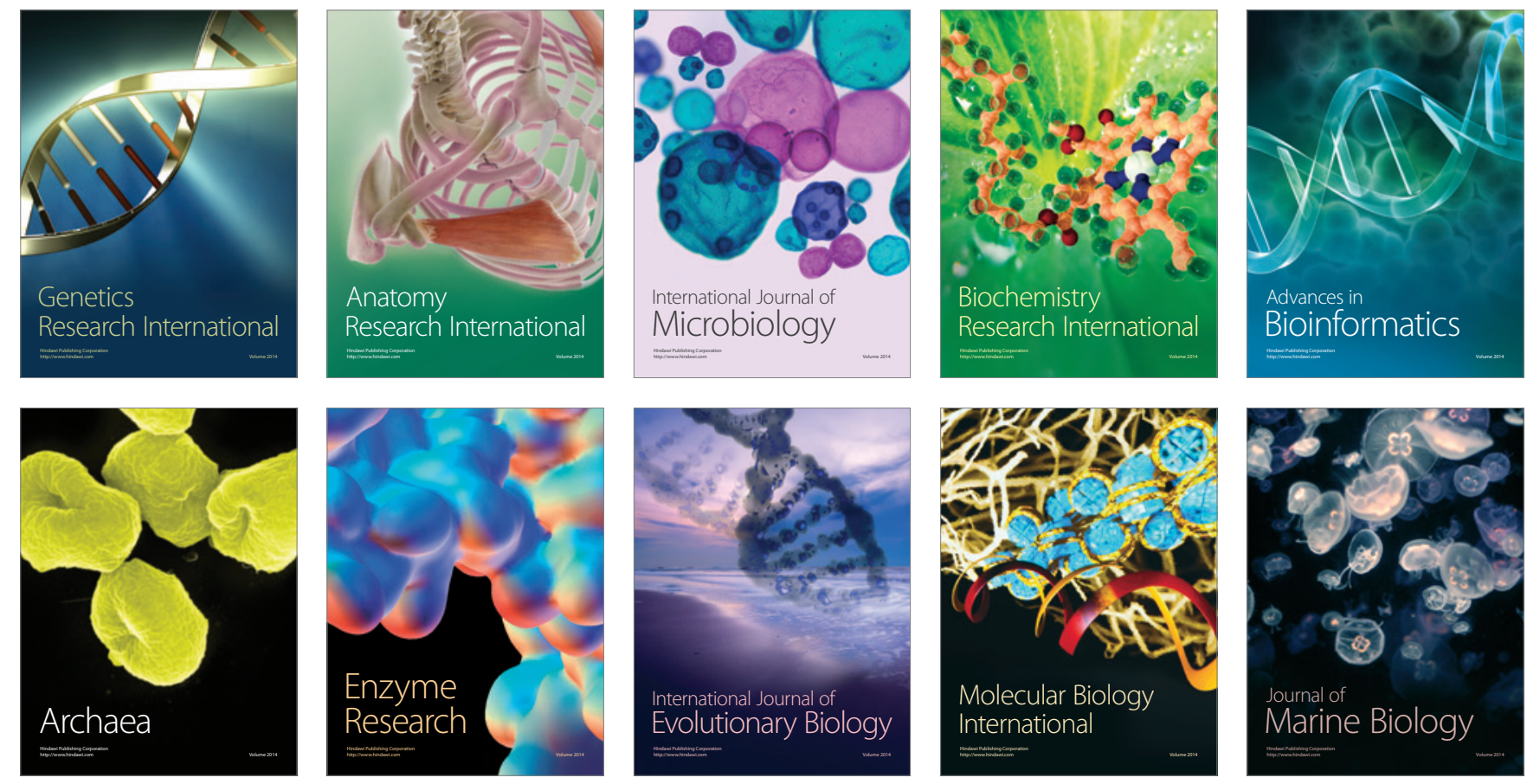